\title{
TOLERÂNCIA À SALINIDADE EM FELJÃO (Phaseolus vulgaris L)
}

\author{
F. BROETTO; G.P.P. LIMA; O.G. BRASIL \\ Instituto de Biociências-UNESP, C.P. 505, CEP: 18618-000- Botucatu,SP
}

RESUMO: Uma das aplicaçōes das técnicas da cultura de tecidos no melhoramento é a identificação de linhas de células que apresentam tolerância à salinidade. Vários autores obtiveram linhas de células tolerantes ao estresse salino; e estudo de mecanismos bioquímicos da tolerância a sais em plantas tem demonstrado altas correlaçōes entre estes e o acúmulo de macromoléculas em tecido de plantas superiores. Para verificar essas correlaçőes em feijão (Phaseolus vulgaris cv IAC carioca), calos oriundos de eixos embrionários foram cultivados em meio sólido, suplementado com $\mathrm{NaCl}$ nas concentrações de 0 a $60 \mathrm{mM}$. Após 13 dias de incubação, os calos foram coletados e analisados quanto ao crescimento relativo, teor de proteinas, teor de prolina e atividade da peroxidase. Os parâmetros analisados mostraram decréscimo no crescimento relativo e no de proteinas em resposta ao $\mathrm{NaCl}$. Paralelamente, observou-se aumento significativo no conteudo de prolina e atividade da enzima peroxidase.

Descritores: cultura de tecidos, prolina, tolerância salina, peroxidase

\section{SALT TOLERANCE IN BEAN (Paseolus vulgaris) CELL CULTURE}

\begin{abstract}
One of the applications of the tissue culture technique in plant improvement is the identification of cell lines which show salinity tolerance. Several authors were able to obtain saline stress-tolerant cell lines and show that mechanisms of tolerance to salts have a strong correlation between this phenomenon and a high macromolecule concentration in plant tissues. Callus obtained from embrionic axis of Phaseolus vulgaris cv. IAC carioca in solid medium, supplemented with 0 to $60 \mathrm{mM} \mathrm{NaCl}$, as the salt treatment, were used. Callus harvesting was done on the $13^{\text {th }}$ day, when they were processed for relative growth, protein, proline content and peroxidase acivity. The results show both, a decrease of the relative growth and of protein content in response to the $\mathrm{NaCl}$ treatment, as compared to controls. However, there was a significant increase on the proline content and on the peroxidase activity.
\end{abstract}

Key Words: plant tissue culture, proline content, salt tolerance, peroxidase activity.

\section{INTRODUÇÃO}

Alguns aspectos metabólicos têm sido estudados em plantas superiores, correlacionados com estresse hídrico. Estudos prévios realizados por BARNETT \& NAYLOR (1966) indicam que ocorre uma diminuição na velocidade de síntese de proteinas e aminoácidos com baixo potencial água. SMITH \& McCOMB (1981), trabalhando com feijão, observaram um decréscimo na taxa de crescimento de calos em resposta ao $\mathrm{NâCl}$ após 28 dias de cultivo.

A síntese de proteina ou a sua hidrólise tem sido verificada em muitas espécies de vegetais cultivadas na presença de $\mathrm{NaCl}$ (LEVITT, 1980). Em feijão, a síntese de proteina foi inibida em solos salinizados por $72 \mathrm{mM} / \mathrm{L}$ com $\mathrm{NaCl}$ (NIEMAN, 1965). STEVENS et al. (1978) estudaram a atividade da peroxidase como parâme- tro de seleção, em espécies brássicas, para tolerância ao estresse salino. Neste trabalho, os autores não encontraram uma correlação entre resposta ao crescimento e mudança na atividade da peroxidase. SAHU \& MISHRA (1987) relataram mudanças na atividade enzimática durante a senescência de folhas, quando submetidas à estresse salino. Os autores observaram que o $\mathrm{NaCl}$ acelerou a atividade da peroxidase, o que estaria relacionado com a regulação da permeabilidade das membranas, formação da parede celular e oxidação de substâncias acumuladas.

\section{MATERIAL E METTODOS}

Sementes de feijão (Phaseolus vulgaris $\mathrm{L}$. Cv. IAC carioca) foram lavadas e desinfectadas em hipoclorito de sódio (1\%) e mantidas por $18 \mathrm{~h}$ em água destilada para hidratação. 
Os eixos embrionários excisados foram inoculados em meio nutritivo MURASHIGE \& SKOOG (1962) contendo sais minerais, ácido 2,4 diclorofenoxiacético, ácido naftaleno acético, cinetina, ácido indolacético, sacarose e inositol, conforme descrito por CROCOMO et al. (1979). Os frascos foram mantidos em sala de cultura com temperatura de $25^{\circ} \mathrm{C}$ e 2000 lux de luz em fotoperíodo de $16 / 8$ horas.

Os calos obtidos foram transferidos para meio de cultura acima citado, suplementado com concentrações de $0,10,30$ e $60 \mathrm{mM}$ de $\mathrm{NaCl}$ e mantidos em condições controladas por 13 dias. Após o tempo de incubação indicado, os calos foram colhidos, pesados e macerados em $5 \mathrm{ml}$ de tampão-fosfato $\mathrm{pH}=6.7,0.2 \mathrm{M}$, seguindo-se uma centrifugação a $10000 \mathrm{rpm}$ por 10 minutos, para obtenção do extrato bruto.

Para se determinar $o$ teor de proteinas usou-se o método descrito por BRADFORD (1976) e como padrão caseina. A determinação da atividade da peroxidase foi realizada no extrato bruto, segundo adaptação do método de EVANS \& ALLDRIDGE (1965). O teor de prolina foi determinado conforme o método proposto por TORELLO \& RICE (1986).

\section{RESULTADOS E DISCUSSÃo}

Analisando-se os resultados apresentados na TABELA 1 para o parâmetro massa da matéria fresca, observou-se que houve um decréscimo no crescimento relativo para os tratamentos 30 e $60 \mathrm{mM}$ de $\mathrm{NaCl}$, quando comparados com o tratamento $0.00 \mathrm{mM}$ de $\mathrm{NaCl}$ (testemunha). 0 mesmo foi observado para teor de proteinas principalmente para o tratamento $60 \mathrm{mM} \mathrm{NaCl}$ (TABELA 2).

TABELA 1 - Massa de matéria fresca expressa em $g$ (médias) de $P$. vulgaris cultivado in vitro na presença de 0 , 10,30 e $60 \mathrm{mM}$ de $\mathrm{NaCl}$.

\begin{tabular}{cccc}
\hline \hline $\begin{array}{c}\text { Tratamentos } \\
\text { mM NaCl }\end{array}$ & $\begin{array}{c}\text { Massa de Matéria Fresca (G) } \\
\text { Tempo (dias) }\end{array}$ & $\%$ \\
& 0 & 13 & \\
\hline 0 & 0.3549 & 0.6450 & 81.74 \\
10 & & 0.6393 & 80.13 \\
30 & & 0.3866 & 8.93 \\
60 & & 0.4792 & 35.02 \\
\hline \hline
\end{tabular}

TABELA 2 - Teor de proteina expressa em $\mathrm{mg} / \mathrm{g}$ m.F. (médias), após 13 dias de cultivo de Phaseolus vulgaris cultivado in vitro na presença de $0,10,30$ e $60 \mathrm{mM}$ de $\mathrm{NaCl}$.

\begin{tabular}{ccc}
\hline \hline $\begin{array}{c}\text { Tratamentos } \\
\mathrm{mM} \mathrm{NaCl}\end{array}$ & $\begin{array}{c}\text { Teor de Proteina } \\
\text { (mg/g m.f.) }\end{array}$ & $\begin{array}{c}\% \\
\text { (controle) }\end{array}$ \\
\hline 0 & 1.683 & 100.00 \\
10 & 1.769 & 105.10 \\
30 & 1.386 & 82.30 \\
60 & 1.308 & 77.71 \\
\hline
\end{tabular}

Para o acúmulo de prolina, verificou-se que o teor deste aminoácido atinge um ponto máximo para a concentração de $30 \mathrm{mM}$ de $\mathrm{NaCl}$, decrescendo um pouco para a concentração de $60 \mathrm{mM}$, quando comparado com o controle (TABELA 3).

TABELA 3 - Teores de prolina expressos em $\mu \mathrm{mol} / \mathrm{g}$ de material fresco de Phaseolus vulgaris cultivado in vitro na presença de $0,10,30$ e $60 \mathrm{mM}$ de $\mathrm{NaCl}$.

\begin{tabular}{ccc}
\hline \hline $\begin{array}{c}\text { Tratamentos } \\
\mathrm{mM} \mathrm{NaCl}\end{array}$ & $\begin{array}{c}\text { Teor de Prolina } \\
(\mu \mathrm{mol} / \mathrm{g} \mathrm{m} . \mathrm{f})\end{array}$ & $\begin{array}{c}\% \\
\text { (controle) }\end{array}$ \\
\hline 0 & 5.82 & 100.00 \\
10 & 10.19 & 175.10 \\
30 & 14.32 & 246.10 \\
60 & 6.49 & 111.50 \\
\hline
\end{tabular}

TABELA 4 - Atividade da Peroxidase, expressa em $\mu \mathrm{mol} \quad \mathrm{H}_{2} \mathrm{O}_{2} \quad$ consumido/min.mg proteina, de Paseolus vulgaris cultivado in vitro na presença de 0 , 10,30 e $60 \mathrm{mM}$ de $\mathrm{NaCl}$.

\begin{tabular}{ccc}
\hline \hline $\begin{array}{c}\text { Tratamentos } \\
\mathrm{mM} \mathrm{NaCl}\end{array}$ & $\begin{array}{c}\text { Peroxidase } \\
\left(\mu \text { mol } \mathrm{H}_{2} \mathrm{O}_{2} / \mathrm{min} .\right.\end{array}$ & $\begin{array}{c}\% \\
\text { mg proteina. })\end{array}$ \\
\hline 0 & 0.038 & 100.00 \\
10 & 0.040 & 105.20 \\
30 & 0.037 & 97.30 \\
60 & 0.046 & 121.05 \\
\hline \hline
\end{tabular}


A atividade da enzima peroxidase foi incrementada significativamente apenas para a concentração máxima de $\mathrm{NaCl}$ utilizada $(60 \mathrm{mM})$, como é mostrado na TABELA 4.

Em função dos resultados obtidos pode-se inferir que, provavelmente, a exposição direta dos calos a concentrações crescentes de $\mathrm{NaCl}$ tenha afetado a absorção de nutrientes orgânicos e inorgânicos, vitaminas e hormônios do meio de cultura. Como consequência, as células iniciaram um processo de degradação de proteínas por hidrólise e, desta forma, um acúmulo de prolina no suco celular (aminoácidos livres). A variação destes compostos influenciou diretamente na taxa de crescimento dos calos, bem como, o acréscimo na atividade da enzima peroxidase pode ter sido causado pela desorganização da permeabilidade das membranas e oxidação de metabólitos acumulados, em resposta ao $\mathrm{NaCl}$.

\section{REFERÊNCIAS BIBLIOGRÁFICAS}

BARNETT, N.M.; NAYLOR, A.W. Amino acid and protein metabolism in Bermuda grass during water stress. Plant Physiology, Rockville, v.41, p.1222$1230,19686$.

BRADFORD, M.M. A rapid and sensitive method for the quantification of microgram quantities of protein utilizing the principle of protein-dye binding. Analitycal Biochemistry, San Diego, v.72, p.248254, 1976.

CROCOMO, O.J.; GALO, L.A.; TONIN, G.S.; SACCHI, N. Developmental control of Phaseolus vulgaris using embryo axis culture. Energia Nuclear na Agricultura, Piracicaba, v.1, n.1, p.55-58, 1979.
EVANS, J.J.; ALLDRIDGE, N.A. The distribution of peroxidase in extreme Dwarf and normal tomato (Lycopersicon esculentum Mill). Phytochemistry, Oxford, v.4, p.459-503, 1965.

LEVITT, J. Responses of plants to environmental stresses. 2.ed. New York: Academic Press, 1980. v.2.

MURASHIGE, T.; SKOOG, F. A revised medium for rapid growth and bio assays with tobacco tissue cultures. Physiology Mantarum, Munksgaard, v.15, p.473-493, 1962.

NIEMAN, R.H. Expansion of bean leaves and its suppression by salinity. Plant Physiology, Rockville, v.40, p.156-161, 1965.

SAHU, A.C.; MISHRA, D. Changes in some enzime activities during excised rice leaf senescence under $\mathrm{NaCl}$ stress. Biochemie und Physiologie der Pflanzen, New York, v.182, p.501-505, 1987.

SMITH. M.K.; McCOMB, J.A. Effect of $\mathrm{NaCl}$ on the growth of whole plants and their corresponding callus cultures. Australian Journal of Plant Physiology, East Melbourne, v.8, n.3, p.267-275, 1981.

STEVENS, H.C.; CALVAN, M.; LEE, K.; SIEGEL, S.M. Peroxidase activity as a parameter for salt stress in Brassica species. Phytochemistry, Oxford, v.17, p.1521-1522, 1978.

TORELLO, W.A.; RICE, L.A. Effects of $\mathrm{NaCl}$ stress on proline and cation accumulation in salt sensitive and tolerant turfgrasses. Plant and Soil, Dordrecht, v.93, n.2, p.241-247, 1986.

Entregue para publicação em 21.06.94

Aceito para publicação em 26.08 .94 